\title{
Laparoscopic Pyelovesicostomy for Ureteropelvic Junction Obstruction in a Pelvic Kidney
}

DAMON E. DAVIS, M.D., and J. STUART WOLF, JR., M.D.

\begin{abstract}
Pyelovesicostomy is an attractive option for treatment of ureteral obstruction in a congenital pelvic kidney or a renal allograft. We describe the first laparoscopic performance of this procedure. The total operative time was 207 minutes.
\end{abstract}

\section{INTRODUCTION}

$\mathbf{O}$ NLY SPORADICALLY DESCRIBED in the literature, pyelovesicostomy is an attractive alternative for treatment of ureteral obstruction in a congenital pelvic kidney or a kidney transplanted into the iliac fossa. ${ }^{1-3}$ To our knowledge, this procedure has not been reported using laparoscopic techniques.

\section{CASE REPORT}

The patient was a 41-year-old man who reported years of right pelvic pain. He was eventually found to have a congenital right pelvic kidney complicated by ureteropelvic junction obstruction. Computed tomography revealed moderately preserved renal parenchyma (Fig. 1). He was referred to our institution for definitive management. The serum creatinine concentration was $1.2 \mathrm{mg} / \mathrm{dL}$ (normal $0.9-1.3 \mathrm{mg} / \mathrm{dL}$ ). The left kidney was normal.

After an informed consent process that stressed the novel aspects of the procedure, we performed laparoscopic pyelovesicostomy. A 12-mm port for the laparoscope was inserted at the umbilicus after transperitoneal insufflation through a Veress needle. Working ports included a 5-mm port above the pubis, a 5$\mathrm{mm}$ port in the right lower quadrant, and a $10-\mathrm{mm}$ port in the left lower quadrant. After opening of the prevesical space, the right side of the bladder was incised to a length equal to an incision made on the medial aspect of the dilated right renal pelvis. Using the Endostitch laparoscopic suturing device (US Surgical, Norwalk, CT), the inferior edge of the vesicostomy was sutured to the caudal edge of the pyelotomy with an absorbable suture in a running fashion. A second absorbable suture was used to close the superior aspect of the vesicostomy to the cranial portion of the pyelotomy (Fig. 2). The bladder was filled, and no leakage was noted from the anastomosis. The estimated blood loss was $100 \mathrm{~mL}$, and the operative time was 207 minutes.

The patient was discharged home 3 days later with a Foley catheter in place. Aside from partial left-hand numbness that resolved within a week, there were no complications. A cystogram performed 8 days postoperatively demonstrated filling of both the bladder and attached right renal pelvis without extravasation. At follow-up 9 months later, the patient reported complete relief of his presenting symptoms, although he did note right pelvic fullness and ache when his bladder was full that resolved immediately with voiding. Intravenous urography demonstrated filling of the right pelvic kidney (Fig. 3A) that promptly emptied into the bladder after voiding (Fig. 3B).

\section{DISCUSSION}

Having been described in the setting of an ectopic pelvic kidney in $1929,{ }^{1}$ pyelovesicostomy was reported as an alternative reconstructive method in cases of ureteral obstruction following renal transplantation by Herwig and Konnak in $1972 .^{2}$ Subsequent indications have included ureteral damage after pyeloplasty, low-grade tumors of the renal pelvis, and to facilitate the passage of renal stones.

Our approach represents a novel application of laparoscopy for this rarely performed but technically straightforward procedure. The disadvantages of pyelovesicostomy might be a risk of progression of bacterial cystitis to pyelonephritis and, as in our patient, pelvic discomfort with a full bladder, but the full-

Department of Urology, University of Michigan, Ann Arbor, Michigan. 


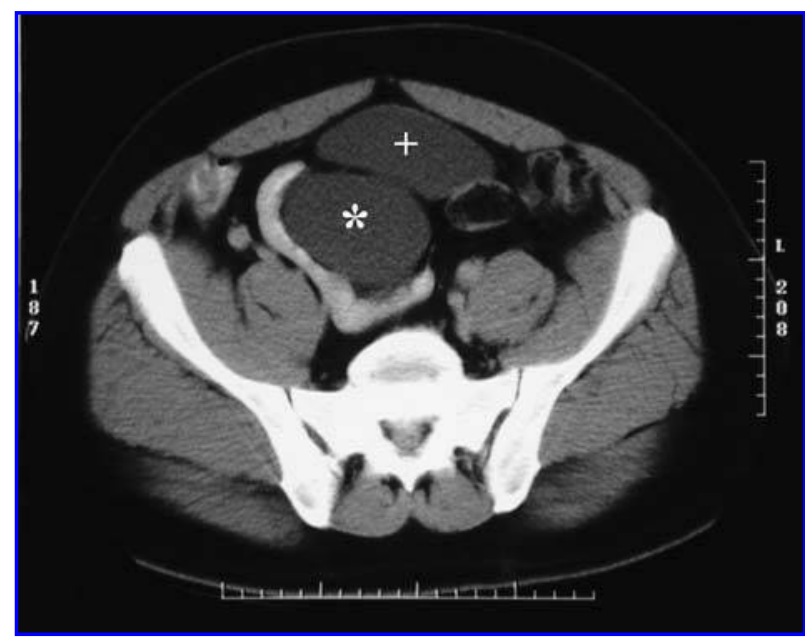

FIG. 1. Preoperative CT scan. *Distended renal pelvis of obstructed right pelvic kidney. + Urinary bladder displaced anteriorly by hydronephrotic pelvic kidney.

A

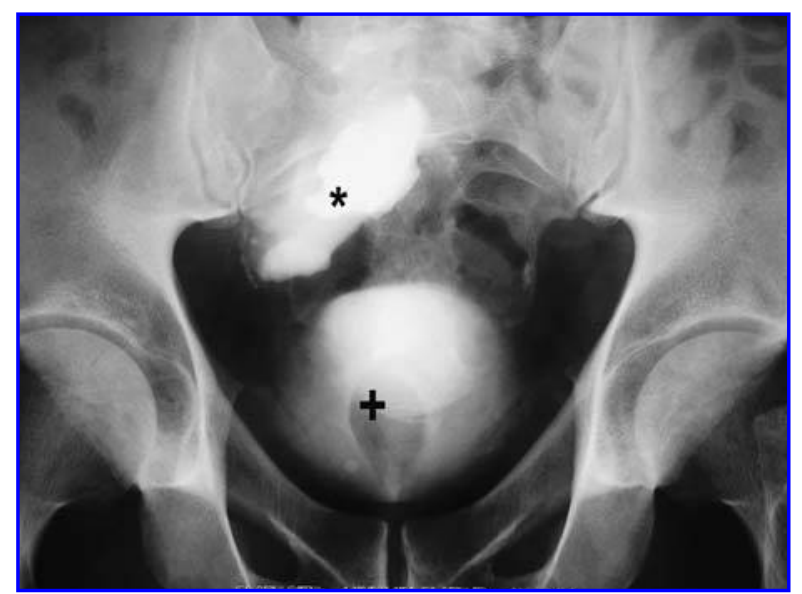

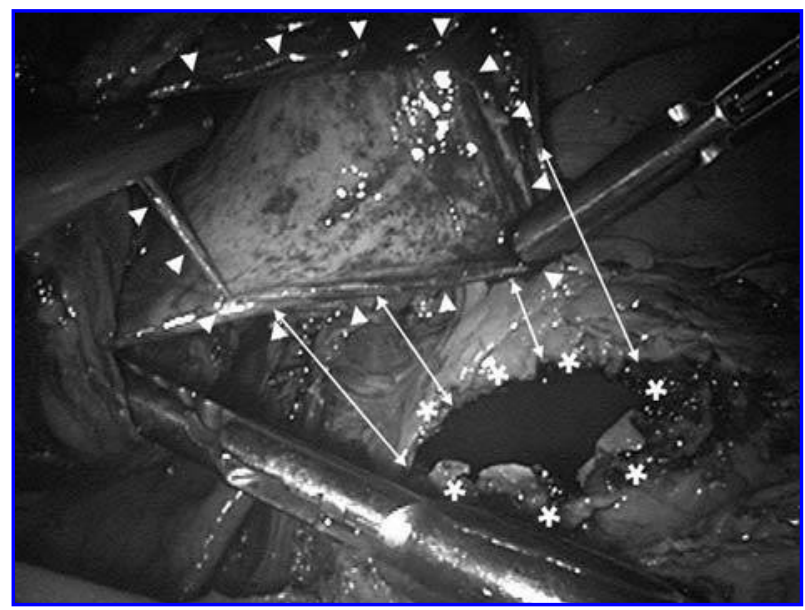

FIG. 2. Intraoperative photograph during pyelovesicostomy, looking down into the pelvis from umbilical port site. Asterisks demonstrate border of vesiscostomy, triangles mark border of pyelotomy, and arrows indicate tissue to be brought together for posterior aspect of anastomosis.

\section{B}

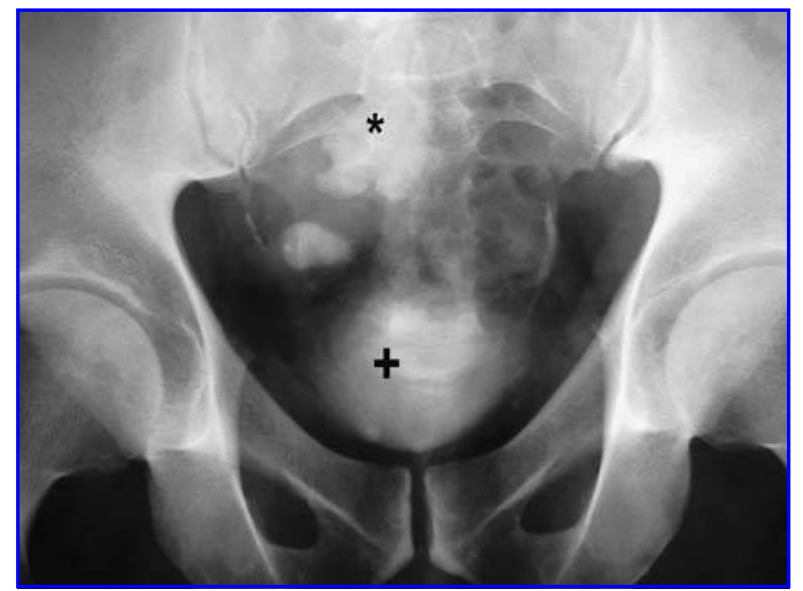

FIG. 3. Postoperative intravenous urogram. (A) Bladder and right pelvic kidney are full. (B) Kidney empties into bladder after voiding. *Renal pelvis of right pelvic kidney. + Urinary bladder.

ness and ache that our patient now experiences is much less than the pain he suffered preoperatively. Given the large caliber of the direct anastomosis between the renal pelvis and bladder, pyelovesicostomy would likely have a lower failure rate than pyeloplasty in this same situation. The ease of the laparoscopic technique is revealed in the short operative time and minimal blood loss.

\section{REFERENCES}

1. Hess, E: Pyelocystostomy (pyelocystostomosis) in crossed renal distopia. J Urol 1929;22:667.
2. Herwig, K. and Konnak, J.: Vesicopyelostomy: a method for urinary drainage of the transplanted kidney. J Urol 1973;109:955.

3. Carini, M., Selli, C., Grechi, G. and Masini, G.: Pyelovesicostomy: An alternative to ureteropelvic junction-plasty in pelvic ectopic kidneys. Urology 1985;26:125.

Address reprint requests to: J. Stuart Wolf, M.D. Department of Urology University of Michigan 1500 East Medical Center Drive Ann Arbor, MI 48109-0330

E-mail:wolfs@umich.edu 
This article has been cited by:

1. Nadya M. Cinman , Zeph Okeke, Arthur D. Smith . 2007. Pelvic Kidney: Associated Diseases and TreatmentPelvic Kidney: Associated Diseases and Treatment. Journal of Endourology 21:8, 836-842. [Abstract] [PDF] [PDF Plus]

2. 2005. LiteratureWatchLiteratureWatch. Journal of Endourology 19:8, 1045-1062. [Citation] [PDF] [PDF Plus] 